\title{
Vulvar Warty Carcinoma
}

National Cancer Institute

\section{Source}

National Cancer Institute. Vulvar Warty Carcinoma. NCI Thesaurus. Code C40287.

A squamous cell carcinoma that arises from the vulva and is characterized by the presence of a warty surface and cellular changes that are caused by human papillomavirus infection. 